\title{
Micromachined Rubber O-ring Micro-Fluidic Couplers
}

\author{
Tze-Jung Yao, Sangwook Lee, Weileun Fang*, Yu-Chong Tai \\ California Institute of Technology, Pasadena, CA 91125, USA \\ *Power Mechanical Engineering, National Tsing-Hua University, Hsin-Chu, Taiwan
}

\begin{abstract}
In this paper, we present a novel type of a "quickconnect" for micro-fluidic devices realized by a simple silicone-rubber O-ring MEMS coupler. As shown in this work, the proposed O-ring couplers are easy to fabricate and utilize, reusable, can withstand high pressure $(>60 \mathrm{psi})$, and provide good seals. In the paper, results from both the leak rate test and pull-out test are presented, demonstrating the functionality of the O-ring couplers.
\end{abstract}

\section{INTRODUCTION}

In the expanding field of microfluidics, it is clear that many micro-fluidic handling devices such as micropump [1], micro-valve [2], and micro-filters [3] have been demonstrated. However for a successful microfluidic system, it is still a very challenging task to connect the external macro-fluidic reservoir to a microfluidic system. This is shown in the rising interest in the development of fluidic interconnects [4-10]. There are still no working MEMS "quick-connect" yet. Some of the micro-fluidic interconnection schemes have been proposed either by conventional precision machining, injection molding or simply by gluing the capillary tubes into micromachined pits fabricated by iso- or anisotropic etching of the silicon substrate. However, injection molding is a relatively complicated fabrication process, and the precision machining is usually bulky. In addition, the gluing of the capillary tubes contributes to a low yield due to misalignment. Thus, in terms of a functional and simple fluidic coupler, new coupling methods must be proposed [7].

In this project, quick-connects that emphasizes reusability and good seal (minimum 10psi) have been successfully developed. Here, we present our first demonstration of a quick-connect coupler between a glass capillary tube and a silicon chip. More than $60 \mathrm{psi}$ seal has been achieved between a glass tube $(860 \mu \mathrm{m}$ O.D.) and a rubber O-ring ( $400 \mu \mathrm{m}$ I.D.) without measurable leakage. The requirements of reusability and good seal are achieved by this new silicone-rubber $\mathrm{O}$ ring technique. In the following, we will discuss the design, fabrication, and complete testing of the device. The extended goal is to achieve easy connection between a multi-port MEMS fluidic device and a fluidic board as shown in Fig. 1.

\section{Design and Fabrication Process}

The initial design of the rubber O-rings are for two sizes of capillary tubes (O.D. $860 \mu \mathrm{m}$ and $640 \mu \mathrm{m}$ ). The process shown in Fig. 2 starts with etching of the silicon substrate to a depth of $250 \mu \mathrm{m}$ by deep reactive ion etching (DRIE) to define the O-ring shape. Then a $2.5 \mu \mathrm{m}$ thick $\mathrm{SiO}_{2}$ is thermally grown to be used as the mask for later DRIE etching. A $1 \mu \mathrm{m}$ thick layer of Silicon Nitride $\left(\mathrm{SiN}_{\mathrm{x}}\right)$ is then deposited on top of the $\mathrm{SiO}_{2}$ to serve as the adhesion layer between the substrate and the silicone rubber. This step is necessary because the silicone rubber does not have very good adhesion on $\mathrm{SiO}_{2}$. After nitride deposition, the silicone rubber is squeezed into the DRIE cavities to form the $O$ ring. The process is then followed by DRIE etching from the backside of the substrate to form the backside hole. The oxide and nitride membranes are then stripped off in buffered hydrofluoric acid (BHF) and $\mathrm{SF}_{6}$ plasma.

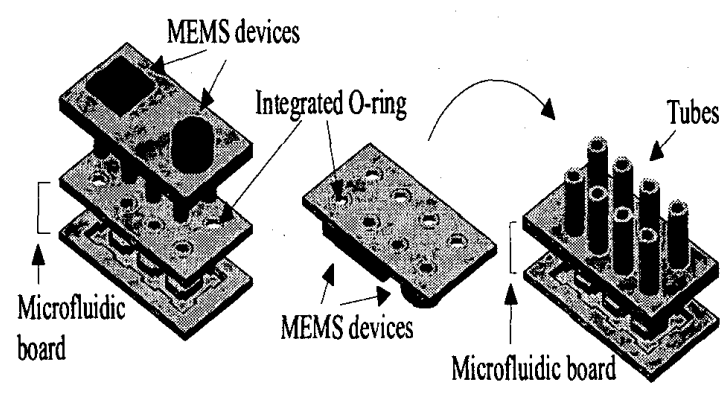

(a)

(b)

Fig.1 Schematic view of the O-ring coupler application (a) A multi-port micro-fluidic device is plugged into a micro-fluidic board with O-ring couplers

(b) A MEMS micro-fluidic device with O-ring coupler is plugged into a micro-fluidic board 
The finished O-ring dimensions are shown in Fig. 3. Various $250 \mu \mathrm{m}$-thick silicone-rubber O-rings have been made. All of the O-rings have the same annulus width $(500 \mu \mathrm{m})$ but with different IDs ranging from 400 to $700 \mu \mathrm{m}$. A schematic view of the couplers is shown in Fig. 4a. After a tube is inserted, the rubber O-ring deforms to establish a good seal, as pictured in Fig. 4(b,c).

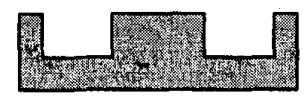

(a) DRIE Front side holes $250 \mu \mathrm{m}$

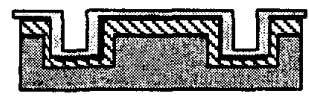

(b) $2 \mu \mathrm{m}$ thermal oxidation and $1500 \AA$ Nitride deposition

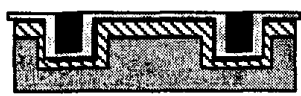

(c) Silicone Squeegee

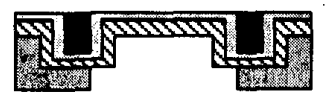

(d) DRIE etch from back side

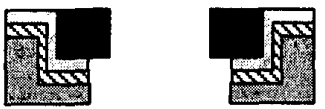

(e) Strip Nitride and

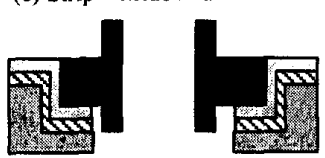

(f) Tube insertion

Fig.2 Fabrication Process for O-ring Couplers

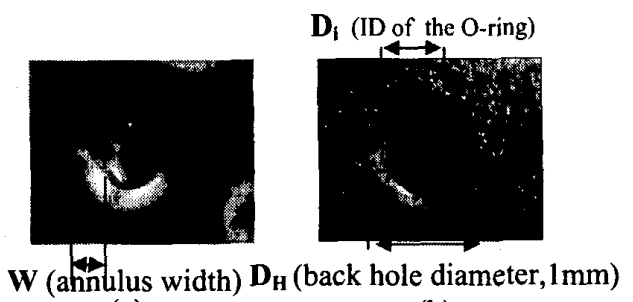

(a)

(b)

Fig.3 (a) A capillary tube plugged into front side (b) O-ring is viewed from back side

\section{Experimental Characterization}

In order to characterize the performance of the rubber O-ring couplers, two of the most important tests are performed - leak rate tests and pull-out force measurements. First, Figure 5 shows the O-ring seals under pressure at $20 \mathrm{psi}$. There is no observable shape change of the O-rings found, which indirectly proves the mechanism of sealing we proposed in Fig. 4a. In short, the good seal is promoted by rubber deformation so that the effective rubber-tube contact thickness is much larger than the original rubber thickness $(250 \mu \mathrm{m})$.

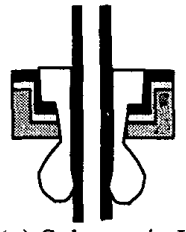

(a) Schematic View

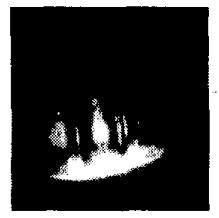

(b) Front

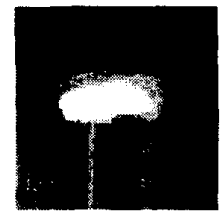

(c) Back
Fig. 4 View of the assembled rubber O-rings and tube structure (a) Schematic drawing (b) front side (c) back Side

After the hypothesis is confirmed, subsequent tests were performed on the O-rings, including the leak test and pullout test. The experimental setup of the leak test is illustrated in Fig. 6. A blocked tube is first inserted into the O-ring chip. The front side is then sealed with a $10 \mu$ micropipette (filled with water to serve as a positive-displacement leak monitor). A pressure gauge is connected to monitor the backside chamber. . The results of the leak test for $860 \mu \mathrm{m}$-OD tube coupled to a $400 \mu \mathrm{m}$-ID O-ring is shown in Fig. 7. A good seal is maintained over $12 \mathrm{hrs}$ with no measurable pressure drop (constant at 20.2psi). The same leak tests have been performed on the other O-ring couplers, with the results given in Table. 1 . We conclude that tight seals can be achieved if the O-ring is properly designed (i.e. the ID of the O-rings is smaller than the tube OD). The experimental setup shown in Fig. 6 can only withstand pressures up to $60 \mathrm{psi}$, with good seals achieved up to that pressure.

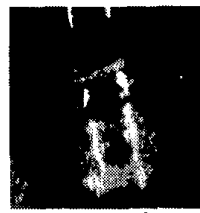

(a) 0 psi

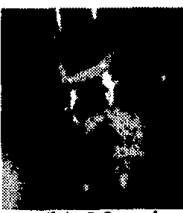

(b) $20 \mathrm{psi}$
Fig.5 Pressure test (a) at $0 \mathrm{psi}$ (b) at $20 \mathrm{psi}$ 
The experimental setup for the pullout test is shown in Fig.8. A position stage is used to pull-out the tube from the O-ring couplers while the load cell is used to measure the resistant force when the position stage moves downward to push-out the tube. As the position stage slides downward and begins to push the tube, the reading on the load cell starts to increase. However, when the tube starts to move relative against the O-ring coupler, the force starts to decrease due to the fact that kinematic friction coefficient is smaller than static friction coefficient. Hence, the maximum reading on the load cell before the tube sliding is recorded in this experiment.

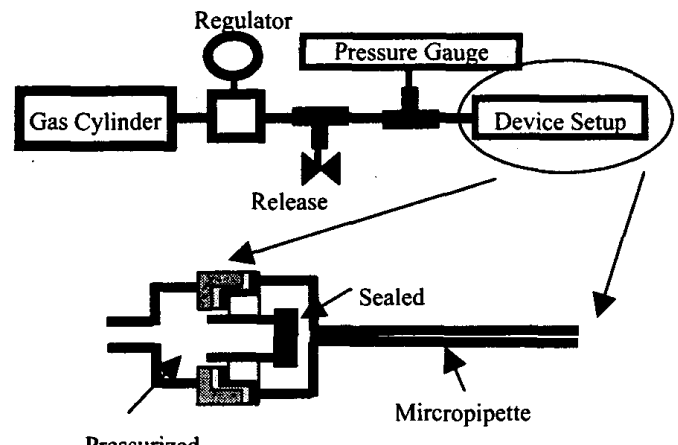

Pressurized

Fig. 6 Experimental setup for leak rate measurement

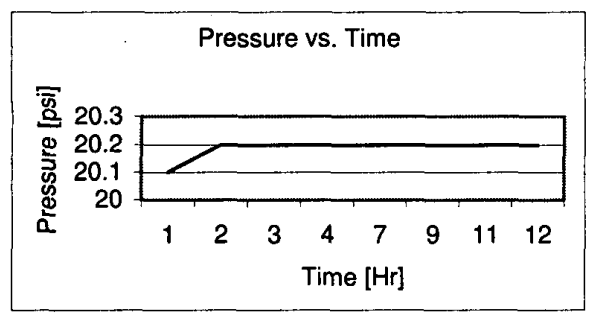

Fig.7 The tube under 20psi remains sealed over $12 \mathrm{hrs}$

\begin{tabular}{|c|c|c|c|c|}
\hline $\begin{array}{c}\text { Tube } \\
\text { O.D. } \\
(\mu \mathrm{m})\end{array}$ & \multicolumn{4}{|c|}{ Inner Diameter of Rubber Mounts $D_{i}[\mu \mathrm{m}]$} \\
\hline & 400 & 500 & 600 & 700 \\
\hline 860 & $\begin{array}{c}\text { Non- } \\
\text { detectable* }\end{array}$ & $\begin{array}{c}\text { Non- } \\
\text { detectable* }\end{array}$ & $\begin{array}{c}\text { Non- } \\
\text { detectable* }\end{array}$ & $\begin{array}{c}\text { Non- } \\
\text { detectable* }\end{array}$ \\
\hline 640 & $\begin{array}{c}\text { Non- } \\
\text { detectable* }\end{array}$ & $\begin{array}{c}1.11 \mathrm{ml} / \mathrm{min} \\
@ 11.5 \mathrm{psi}\end{array}$ & Infinite** $^{\text {Infinite** }}$ & \\
\hline
\end{tabular}

Table 1 Leak rate test on different tube diameters vs. inner diameter of Rubber O-rings.

*Non-detectable $(<<0.1 \mathrm{ml} / \mathrm{min} @ 20 \mathrm{psi})$

**Infinite (>10ml/s @ 0.5psi)

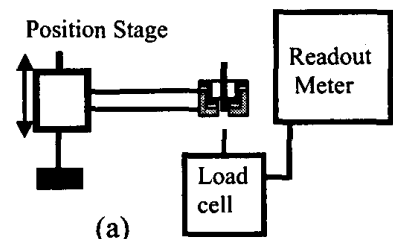

(a)

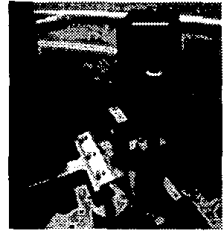

(b)
Fig.8 Experimental setup of pull-out test

(a) Schematic view (b) Photo of setup

The results of pull-out measurements are shown in Fig. $9 \mathrm{ab}$. The results suggest that the force required to pull the tube out of the O-ring decreases as O-ring ID increases. Figure $9 \mathrm{~b}$ shows the calculated theoretical holding pressures converted from the data in Fig. 9a. A wide range of holding pressures (all $>10 \mathrm{psi}$ ) has been achieved with the maximum around 80 psi for the tube with OD $860 \mu \mathrm{m}$ against the O-ring ID $400 \mu \mathrm{m}$. And all the results agree with our leak test data.

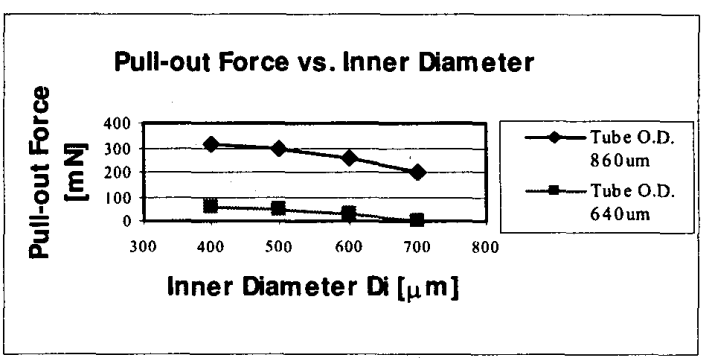

Fig.9a Pull-Out Force vs. Inner Diameter of rubber O-rings

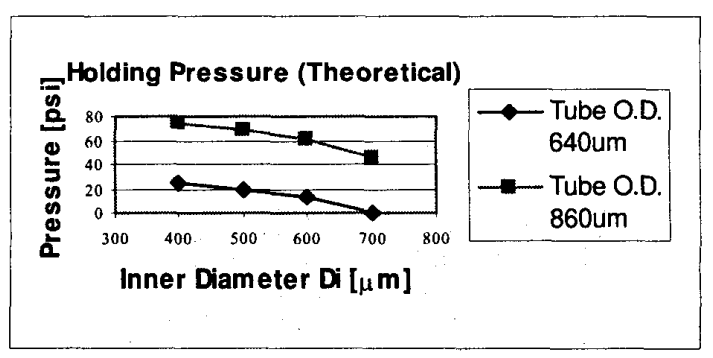

Fig.9b The Theoretical Holding Pressure calculated from Fig.9a

\section{Reliability Test on O-ring Couplers}


Finally, the pull-out tests were repeated several times to simulate the reusability of the devices (Fig.10). We observe that stabilization is reached after several cycles (showing no further decay), indicating reliability of the devices. A repetition test ( $>200$ times) has also been performed, showing good adhesion between rubber and nitride side-wall. In a few instances, cracking of the $\mathrm{O}$ rings around the inner diameter of the rubber membrane was observed. This problem is expected to be easily solved by using different silicone rubbers as O-ring materials.

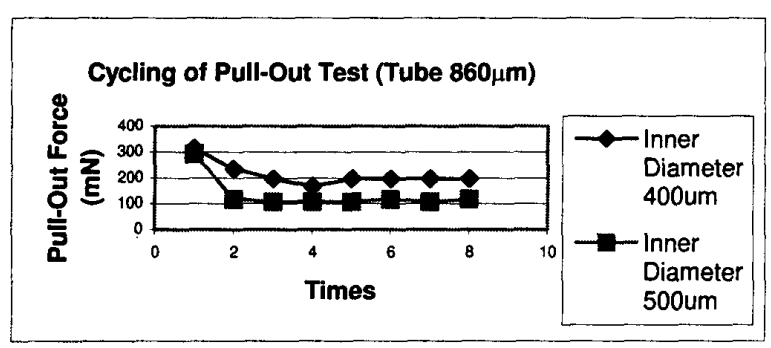

Fig.10 Cycling test of pull-out force on rubber O-rings

\section{Conclusion}

In this paper, a micromachined rubber O-ring coupler has been designed, fabricated and tested. The result shows the coupler is reusable and can maintain good seal as high as $60 \mathrm{psi}$. The next step of this project will be putting micro-fluidic devices and the couplers together to make the micro-fluidic board as we proposed in the Fig.1.

\section{Acknowledgements}

The authors would like to thank our colleague, Charles Grosjean, for constant suggestions and assistance on the device fabrication for this project.

\section{References}

[1] C. Grosjean and Y.C. Tai, "A Thermopneumatic Peristaltic Micropump", Hilton Head '99, pp.1776-1779

[2] C. Grosjean, X.Y. Yang, and Y.C.Tai, "A Practical Thermopneumatic Valve," MEMS '99, pp. 147-152

[3] X. Yang, J.M. Yang, X.Q. Wang, E. Meng, Y.C. Tai and C.M. Ho, "Micromachined Membrane Particle Filter", MEMS '98, pp. 137. 142
[4] D. Jaeggi, B.L. Gray, N.J. Mourlas, B.P. van Drieenhuizen, K.R. Williams, N.I. Maluf, and G.T.A. Kovacs, "Novel Interconnection Technologies for Integrated Microfluidic sytems", Hilton Head '98, pp. 112-115

[5] D. VerLee, A. Alcock, G. Clark, T.M. Huang, S. Kantor, T. Nemcek, J. Norlie, J. Pan, F. Walsworth, S. T. Wong, "Fluid Circuit Technology: Integrated Interconnect Technology for Miniature Fluidic Devices", Hilton Head '96, pp. 9-14

[6] N.J. Mourlas, D. Jaeggi, N.I. Maluf, and G.T.A. Kovacs, "Reusable Microfluidic Coupler with PDMS Gasket”, Transducers '99, pp.1988-1989

[7] S.F. Trautweiler et al, MEMS '96, pp. 61-66

[8] T.S.J. Lammerink, V.L. Spiering, $M$. Elwenspoek, J.H.J. Fluitman and A. van den Berg, "Modular Concept for Fluid Handling Systems”, MEMS '96, pp.389-394

[9] R.J. Reay, R. Dadoo, C.W. Storment, R.N. Zare, and G.T.A. Kovacs, "Microfabricated Electrochemical Detector for Capillary Electrophoresis", Hilton Head 94, pp.61-64

[10] N.J. Mourias, D. Jaeggi, A.F. Flannery, B.L. Gray, B.P. van Drieenhuizen, C.W. Stormant, N.I. Maluf, and G.T.A. Kovacs, "Novel Interconnection and Channel Technologies for Microfluidics", Proc. Of the Micro Total Analysis Systems Workshop '98, pp. 27-30 